\title{
Quo Vadis? \\ A View from India on General Insurance Industry in Developing Countries
}

\author{
by R. D. Samarth *
}

\section{New international environment}

The 8th Congress of Third World Insurance Countries, held in Delhi from 17th to 21 st of February 1992, is of historic importance. It should mark the beginning of a new phase in the development of our General Insurance Industry in the new international environment arising from the drastic political and economic changes which have occurred in the global arena in the unforgettable year 1991. The scenario, however sombre, has its touch of humour too. On the one hand the collapse of the state controlled economies in Eastern Europe and USSR has been too sudden for smooth intake even by the bitterest critics of socialist systems. On the other, the emergence of frontierless markets in Western Europe and North America is too slow for overenthused votaries of the free market. Total collapse of state managed economies in most of the countries of the historical Eastern block and continuation of the dismal economic performance of most of the members of its counterpart in the Western world prove that neither Adam Smith nor Karl Marx can provide a panacca for curing all the economic ills of our society in the environment generated during the past five decades by an intricate mix of political, socio-economic, ethical and technological forces.

\section{Common approach for future development}

Insurance Industry, born of a multi-dimensional evolution of human society, is bound to undergo during the last decade of this Century radical transformation in tune with the change in the characteristics of human society. It is therefore vitally important for the underwriters of the Third World Insurance Industry to pause and ponder over the direction Third World Insurancc Industry should take if it is to make, during this dynamic phase of human history, a valuable contribution to the socio-economic welfare and technological advance of our people. The strategy to be adopted by individual members of TWIC will vary in detail to suit the diverse multi-dimensional backdrop of each country and yet in macro terms it is likely that we can evolve a common approach. In planning

* Former General Manager of New India Assurance Company and member of Faculty of the National Insurance Academy. Pune. India. Text presented at the 8 th Third-World Insurance Congress, New Delhi, February 17-22, 1992. 
our strategy in order to perform successfully in the coming years, the role of providing an umbrella of security for technological advance and the socio-economic welfare of the community, we will have to raise some fundamental issues for consideration by not only insurers and the officials of Ministries by Finance, but by all sectors of the community. Unless there is integrated involvement of all sectors of the community in operating the insurance industry, this experiment, which, in its rudimentary form of bottomry, was the primary pragmatic collective response for protecting the expanding frontiers of international trade and culture against the vagaries of change, will cease to exist as an independent form and become host among the many elements of a multi-dimensional financial supermarket. Since my own experience of insurance is limited to the field of the General Insurance Industry, consideration in this article will be confined to that sector of insurance business.

\section{Review of past operations (1950-90)}

In successfully planning our operational strategy to achieve in the coming years the twin objectives of providing a community umbrella of security for technological advance and socio-economic welfare, whilst maintaining growth on a sound profitable basis, it is imperative to make an analysis of our industry's strengths and weaknesses as developed over the past four decades.

\subsection{Our strengths are as follows:}

3.1.1. With approximately $60 \%$ of 1300 companies operating in Third World countries from local units, structural transformation of our industry from foreign control to a predominantly localised norm has been achieved smoothly and further transformation to suit changes in the socio-economic technological environment is expected to continue progressively manner without disruption in operations.

3.1.2. The performance of our industry during the preliminary phase of restructuring has been satisfactory from the growth and profitability standpoints. An insurance infrastructure for servicing the needs of commercial and industrial sectors is now well established. There has been substantial progress in some countries, and a good beginning made in others in providing insurance services for satisfying the needs of the community in the rural sector and low income groups.

3.1.3. In spite of the predominantly competitive environment of developing markets ( $75 \%$ Free, $25 \%$ Nationalised) it has been possible for our underwriters to earn an adequate underwriting surplus during the sixties and seventies and at least a marginal surplus during the eighties. Significant steps have been taken in most of the markets either in the form of insurance legislation or voluntary restrictions by Tariff Associations to keep within reasonable limits commission and expenses and thus to protect underwriting profitability against impact of inflationary economy. The profitability of operations in the formative stage of industry has helped to incrcase shareholders' funds. Industry has been able to give a good return in dividends to private and public sector shareholders and to make a positive contribution to the promotion of National Schemes for Socio-Economic Welfare.

3.1.4. Basic insurance technology has been absorbed and training of local manpower has significantly reduced operational dependence upon expatriate personnel. A fruitful 
beginning has been made for co-operation within the Third World insurance community in training activities reducing to a considerable extent exclusive dependence on insurance institutes from Western countries.

3.1.5. The international market has welcomed the stability generated by the structural transformation of developing insurance markets. Underwriting profitability of business made markets of developing countries during the sixties and seventies attractive for international reinsurers and competition in reinsurance markets for good quality business produced favourable commission terms reducing our net cost of reinsurance programme. Good beginning has been made with promoting reinsurance arrangements within the Third World region through the establishment of regional reinsurance companies and pools.

3.2. As against these strengths, our weaknesses can be identified as follows:

3.2.1. Development of our insurance portfolio has focussed excessively around the cluster points of commercial and industrial risks exposing our industry to the danger of stagnation, should the wheels of commerce and industry slowdown during the recessionary phase of the economic cycle. The twenty percent growth rate of our industry in the sixties and seventies, when our economies were reasonably exuberant, has declined to a marginal level under $5 \%$ during the present recessionary phase. Our portfolio is not broadbased as can be seen from the average premium density of $0.5 \%$ of GNP as compared to $3.5 \%$ for the developed markets.

3.2.2. During the eighties the underwriting profitability of our business has declined steeply, particularly in the major sector of Motor insurance. Unless underwriting profitability in this sector which now forms approximately $30 \%$ of our portfolio is restored at least to a marginal level, there is little possibility of arresting continued decline of overall underwriting profitability and its deterioration into underwriting deficit, as has been the case in the insurance markets of developed countries. Under the pressure of competition in free markets and due to the impact of growing consumerism in nationalised markets, the non-motor portfolio is now written at premium and commission rates which at best produce an average underwriting surplus of $5-7 \%$ and is in no position to absorb heavy underwriting loss under Motor portfolio.

3.2.3. Profitability of business during the initial years has resulted in the payment of high dividends to shareholders which adversely affected the growth of reserves limiting thereby domestic capacity to retain business. Profitability of business motivated formation of new companies entailing fragmentation of markets by the multiplication of financially weak companies operating as fronting units for foreign insurers. As concerns the retention of premium in the domestic markets, excessive expansion of our local industry units has produced unsatisfactory results.

3.2.4. In the case of nationalised monopoly markets, excessive interference from bureaueracy and political circles has adversely affected growth and profitability of business. Political interference results at times in the exposure of the limited funds of the insurance industry to write schemes for socio-economic welfare without properly developing either appropriate technology or a suitable infrastructure for the administrative control and servicing of business. The unseen hand of the market operates even in monopoly sectors. If operational efficiency is not satisfactory, prospective clients utilise their available surplus from savings for purchasing security from other sources of investment. Policy- 
holders express their dissent by minimisation of insurance needs to statutory and commercial obligations. As against the insurers lack of choice in monopoly markets, in excessively competitive markets insurers at times mislead customers into buying spurious products resulting in the loss of credibility for insurance at the time of unsatisfactory processing of client's claims. Mixed markets with simultaneous operation of public and private sector companies produce problems of interrelation due to the priority given generally by governments to public sector companies for insurance of major state-financed risks, leaving the private sector companies to compete aggressively for the limited balance of business at inadequate rates to the detriment of the health of the insurance market.

3.2.5. Intensive economic recession in many developing countries has resulted in serious foreign exchange problems causing inordinate delays in the settlement of reinsurance balances and the decimation of reinsurers' locally retained funds owing to devaluation of national currencies. These factors have significantly reduced the attraction in international reinsurance market of business from developing countries, thereby causing difficulties for the arrangement of reinsurance treaties on our business particularly in the case of markets exposed to catastrophic losses due to natural hazards. With this hardening attitude of foreign underwriters, it is becoming difficult at times to place in the international market reinsurance on our target risks particularly with linkage to liability aspects, leading thereby to the situation either of inadequate insurance on our high technology risks or the payment of exhorbitant prices for restrictive cover. With only $4 \%$ of the global premium of US $\$ 500$ billion from Third World sector, our industry will depend to a substantial extent on financial capacity of developed insurance markets for our reinsurance

needs. Regional reinsurance companies formed during the past three decades in the Third World sector have made a good beginning but cannot in foreseeable future substitute to any appreciable extent the reinsurance capacity we require from the developed markets.

\section{Multi-dimensional management strategy for the decade of turbulence}

Based upon our pragmatic assessment of strengths and weaknesses, we should formulate with clarity of purpose our operational strategy for dealing with the following problems during the decade of 90) designated by futurologists as the 'Decade of Turbulence'.

\subsection{Structural transformation and the dominant role of local industry}

As stated in the introduction to this article, privatisation of all sectors of human enterprise has become the predominant theme of the present-day international scenario. In spite of the din and noise made by the champions of free markets, dispassionate analysis of trends for socio-economic models reflecting society's technological level indicates that by the end of this decade a varied mix of liberalisation and state control will become established in all parts of our globe. Unless a symbiotic relation between the state control-agencies, production sectors and consumer communities is established in all categories of human activity, there is no hope for a revival of productivity in the economic sector or for a restoration of creative stability in the socio-political life of modern society which has continued its galloping technological advance. A limited number of mega-size units are likely to control all sectors of our economic enterprise subject to effective operational control by legislation through the agency of the state and by market forces through various fora of consumers and citizens. Insurance industry's structure in all sectors of the international market will undergo transformation in tune with the socioeconomic-political norm evolving in various countries. At this stage, it would therefore 
be judicious to review the operation of our industry in its different modes, Nationalised, Localised or Free, prevalent in various markets of the Third World region and to initiate changes for strengthening positive elements in our systems and eliminating distortions. Drastic changes like the total privatisation of Nationalised insurance industry or opening Localised insurance markets to foreign enterpreneurs or immediate merger or deregistering of small and medium size companies operating in our Free markets will be far more damaging for the future development of our domestic industry than our obstinate refusal to introduce necessary reforms for rectification of defects. Structural transformation of our industry in different forms suitable to the diverse socio-economic-political environment evolving in each country is vitally important to its growth and profitability, but at this stage we should not overlook the objective of securing a dominant role for the Third World's Domestic Industry and protecting it against take-over by Developed Markets in the name of Integration into the Global Economy. The structural transformation of our industry should not be at the cost of losing our independence of operation and returning to the state of appendage to the insurance industry of the developed countries as was the case in the pre-independence era.

\subsection{Financial strength and market retention capacity}

As highlighted in the discussion on our weaknesses, many of our markets are excessively fragmented for the market potentiality level. In-depth analysis should be made of this aspect of our markets for it is the weak spot in our defence against the re-entry of financially strong companies from developed markets into our region, through various forms of joint ventures or takeovers. $97 \%$ of the Japanese Insurance Market with its premium of 70 billion US $\$$ is controlled by only 22 local companies. The strength of the Japanese insurance market basically derives from this primary structural characteristic. Voluntary limitation of the number of units operating in our markets is necessary for protecting the financial health of our market. Provisions for paid-up capital and solvency margins should be revised upwards to adequate levels for ensuring the financial strength of insurers and security of policy holders. This step will encourage voluntary mergers and the shrinkage of markets to match potentiality levels. Intensive competition amidst a limited number of operating units, as has been the case in Japan, with the growing strength of consumer movements in all markets of our region will secure the benefits of excellence of service to our clients at an economic price. In the case of our nationalised markets, companies' financial reserves should be carefully built up and dissipation of surplus through payments of high dividends to government should be discouraged. Through investments and income tax payments, the public sector insurance industry conducting business on a sound profitable basis can make a vital contribution to the national economy. It is therefore of paramount importance that its financial reserves are built up swiftly so as to expand its capacity to retain business within a country and thus diminish an excessive flow through reinsurance. The same approach in respect of the payment of dividends should be adopted by private sector insurers for strengthening their reserves and increasing thereby the market's collective retention capacity.

\subsection{Prospects for the resurrection of underwriting surplus}

The financial reserves of our industry derive from our operational surplus. If this source drys up as has happened in the case of the developed insurance markets exposed to the pressure of excessive competition. our industry's survival will depend exclusively 
on investment income seriously weaken our defence against takeover by the multidimensional financial supermarket. For our survival as independent financial enterprises, it is imperative that our markets follow the basic rule of writing business with a reasonable underwriting surplus and discard the pernicious practice of cash flow underwriting which generates a perpetual cycle of chasing claims by increasing premia, both contributing to inflationary upwards trend of the economy. Insurers in developing countries should educate the community at large in an appreciation of the reasons for unsatisfactory trends in the availability of an insurance service at a reasonable price in the vitally important sectors of Motor, Health, professional and products liability and agriculture. The reasons for the failure of insurers in the developed markets of Europe and the U.S.A. (and the comparatively reasonable success of Japanese insurers) in these fields should be discussed in public forums and, through consensus, solutions should be found suitable to the local environment for providing these vital insurance services so necessary to socio-economic development and welfare. Market forces will not by themselves resolve the riddle of providing a service at a reasonable cost to clients and at least marginal surpluses to underwriters, in insurance classes linked to social welfare of community. The insurance needs of the commercial - industrial sectors can be met at a reasonable price for clients and ensure a satisfactory surplus for underwriters through a discrete link between rates and risk management techniques. To summarise: if the Third World insurance industry desires to preserve its independent identity and avoid being sucked up by the powerful draft of the multi-dimensional finance machine, restoration of underwriting surplus in our business operations is a must. Restoration of the underwriting surplus will have a beneficial effect on our reinsurance arrangements by way of excellent terms for commission and profit commission available on attractive portfolios in a competitive international reinsurance market.

\subsection{Strategy for vigorous multi-sectoral growth}

Most of the developing countries had in the initial post-independence decades registered impressive economic growth rates, but for reasons peculiar to each country, this could not be sustained during the following decades except for the continuing brilliant performance of the export-oriented economies of some countries in South-east Asia and the Far East. In spite of this unhappy situation, in most of our countries, there is development of a consumer's market of reasonable size with potential for insurance needs centred round purchase of a house and a vehicle, personal safety and health. The percentage of savings to GNP is as high as $20 \%$ in some of our markets and if skillfully tapped, through design of savingslinked personal insurance packages, this hidden potentiality could be a vital source for future development. Japan's experiment in the development of personal insurance business to the extent of $35 \%$ of the overall portfolio by discrete use of savings-linked schemes should be studied carefully for planning our strategy in this direction. Skewed development of our business portfolio through over concentration on commercial and industrial units could be rectified with development of personal insurance on a broad basis. Socio-economic welfare schemes for catastrophe-prone regions can be designed through insurance as a joint exercise by government, multifarious community-organisations and the insurance industry. Collective efforts should be made to develop a marine insurance portfolio for our industry with promotion of bilateral and multilateral agreements for insurance on import-export trade within the region of Third World countries. Lifting the insurance density of our region from $0.5 \%$ to $3 \%$ of GNP during the $90 \mathrm{~s}$ is a practical proposition even at the marginal 
economic growth rate of $3 \%$, predicted by World Bank economists, if the insurance infrastructure established during the past 3 decades is utilised by our insurance personnel with enthusiastic commitment to the development venture.

\subsection{Adequacy of technical expertise for the problems of a dynamic environment}

In the preliminary phase of our development, we have absorbed adequate insurance technology to provide traditional types of insurance service to our clientele. In a dynamic environment, now we have to reduce our dependence on foreign expertise in underwriting the risks of complex technology. In our various markets, there is a peculiar need for specialisation in the insurance of special kinds of complex technology. Expertise developed in various countries can be gainfully utilised in establishing research institutions at regional centres to avoid duplication of costs and for making wider use of the expertise. Research activity should be applied to promoting insurance schemes for rural and agricultural sectors which contribute a significant share to the GNP of many countries. The objective of providing adequate insurance cover through package schemes on an all-risk basis, on lines similar to the developed markets, can be reached through linkage of Risk Management techniques and insurance programmes. For efficient servicing of clients, in times of need, claims management techniques have to be developed on a par with developed markets. Use of computerised systems for information analysis should be developed for the scientific underwriting of high technology risks and natural hazard portfolios. Efforts should be made to develop of regional expertise for surveys in the field of Marine Hull and Aviation portfolio. Individual and collective upgrading of our overall technical expertise must be achieved through regional training and research centres, if our industry is to develop vigorously on a sound profitable basis without surrendering ground to pools, specialised mega-size units' controlled captives and offshore insurance arrangements, the formation of which may be encouraged in our markets by technically advanced advisers from forcign countries in the present international environment conducive to such enterprise.

\subsection{A new management norm through the fusion of modern technology and traditional ethos}

Barring the significant exceptions of Japan and Germany, all other nations irrespective of their political or economic ideologies have witnessed during the past four decades continuous decline in productivity or organisations in all sectors of enterprise. For achieving our growth objective of raising to a reasonable level the premium density of our insurance markets, it will be vitally important to build a vibrant insurance organisation. Our organisations will be vibrant, only if there is extensive participation of all members of the organisation in their operation. As pointed out by Mr. Gunnar Myrdle in his book 'Asian Drama', "the attempt to usher technological - socio-economic revolution through the management system designed for colonial administration has largely defeated its own purpose, in spite of heavy investment in established infrastructure". Solutions to our management problem must be in tune with our traditional ethos. Japan's success in the field of management is through their judicious mix of high technology and traditional sociology. The joint family system or traditional community organisation has been the basic feature of society in most Third World countries. Against this cultural backdrop, participative management seems to be the most suitable way for an organisation to optimise its productivity. A sense of ownership in an organisation, in the private or public sector, will release an employee's full dynamic potential. Decentralisation of authority and full scope for individual initiative will inject enthusiasm into members of an organisation at all levels making it a vibrant medium for providing an excellent service to the customer and. simultaneously for safeguarding the 
operational interests of an organisation. Maximum use of tradition and culture should be made by us in finding solutions to our management problems and apish imitation of Western management schools should be abandoned. Optimum use of computerised systems for operational efficiency in our organisations should be made subject to the contstraint of our social responsibility for providing a gainful source of employment for our people. Computerised systems should be suitable from the appropriate technology standpoint and wastage of financial resources in updating technology from time to time should be avoided. Third World countries should protect themselves from technological seduction in the currently gullible atmosphere of the free flow of technology from the developed world at a high price to the developing client. Even after two centuries of operating an insurance industry in developed countries, public perception about our socially valuable role as "Trustees of Community Welfare" is not appreciated. Insurers are in the common man's view "Invisible Bankers". If such is our industry's image in developed markets, we can very well imagine the apathy of the common man towards utility of insurance in our developing countries. For vigorous growth of our industry, it is vitally important to involve the representatives of the community at large in the management and ownership of our industry. Appointment of representatives of the various sectors of our society, commercial, industrial, professional and agricultural to the boards of our insurance companies in the private or public sector will go a long way to generating right perception of our role in national enterprise for the socio-economic - scientific and cultural development of our people. Business based upon the principle of "Utmost Good Faith" can be managed properly only with the enthusiastic involvement of our clients alongwith our employees and shareholders. All management theories have now reached their ceiling in producing a creative fusion between collective productivity and individual happiness. The time has come for New Concepts of Management, fusing dynamic technology with the traditional cthos, which in its brilliance will melt the virus of hybrid commercialisation, polluter of forms of human enterprise, though born of the pious intention of promoting universal peace, progress and happiness.

\subsection{The symbiotic co-existence of diverse operational norms}

The biggest challenge which insurance professionals in the international insurance market have to face in the dynamic 90 s is to make a vital contribution to strengthening bridges of understanding among all nationalities inhabiting mother earth. Better than all others, professional insurers understand, on the one hand, the strength and frailties of the human mind and, on the other, the power and failures of advancing technology. It was with remarkable resilience that excellent relations were developed between the well-established insurance industry of the colonial powers and the newly emerging insurance industry of liberated countries. The nationalised and localised insurance industry in many Third World countries at present enjoys good support in terms of reinsurance relations and transfer of technology with the traditional markets of the Western World. This situation of the mutually beneficial co-existance of diverse forms of insurance industry should be now protected against the efforts of some aggressive advocates of Frontierless Markets. The Retention of barriers in the advanced insurance markets of Europe and North America may rightly be regarded as a hindrance to the further development of an advanced insurance industry as a new and integral part of the financial supermarket. On the contrary, retention of barriers in insurance markets of developing countries will at this stage be essential for their sound growth. With advanced technology and management expertise at their command 
insurers in developed countries have not been able as yet to arrest the assault of market forces and recover the even marginal underwriting surplus lost during the post-war decades. It is for the Cash Flow Underwriters in the developed markets to consider whether to accept without resisting the ultimate merger of their General Insurance Industry in the financial supermarket or to combat it by a drastic restructuring of industry through integrated collective efforts for reviving some valuable old concepts and systems of insurance management, even if this invites criticism from overenthusiastic advocates of the free market. If, after cool consideration, Western Insurance Experts arrive at the conclusion that an independent General Insurance Industry has now become in their markets anachronistic and merger in the financial supermarket is the logical end of the road travelled thus far, they may sing its swan song and prepare by the end of this decade to drop the curtain on the General Insurance Industry on the Western stage. They should not however, in the aggressive mood of converts to a new faith, release international monetary pressures in the name of globalisation of the Insurance Industry, and so damage the prospects for healthy growth of an independent General Insurance Industry in the developing markets of the Third World. Japan's General Insurance industry which has evolved its own norm of limited competition in a free market, subject to intensive consumerist control, producing consistent growth of business with reasonable profitability for insurers and excellence of service at economic prices to clients, has provided a fine example of a structural norm for the survival of an independent General Insurance Industry. It is in the interest of our global insurance industry that, irrespective of structural diversity, the industrics of developed and developing countries continue to co-operate in a healthy exchange of business and transfer of technology for mutual benefit. Within the group of developing countries, the movement for co-operation in expanding our industry in all directions should gather increasing momentum. Whe should aim at development which will initially enable us to establish frontierless markets within our immediate neighbourhood. With the passage of time, we can expand our barrierless territory to meet the fraternity from the developed world on common ground. To achieve this goal, we should study the developments in the advanced markets of the U.S.A., Europe and Japan and for sound growth of our marketing management formulate strategies suited to the evolving socio-economic-technological environment. It will be a matter of professional pride and deep satisfaction for all of us, if in the XXIst Century the General Insurance Industry in our part of the glob shows vigorous and independent growth, making a valuable contribution to socio-economic welfare and the technological advance of our people, and thereby fulfilling the historical mission for which insurance activity was started in the earliest form of bottomry contracts in Hamurabi’s Babylonia - A Third World Country.

\section{The emergence of a brave new world}

It is interesting to note that in 1950 , when the dark clouds of the cold war had darkened the international horizon, insurance professional Jaroslav Tuma concluding his "Primer of the Theory of Administration" had the exceptional insight and courage to predict: "The two opposing political orders, capitalist or liberal and solidaristic or communist, in which the World is divided, will in due course reach a compromise, each one accepting some principles from the other and produce a new international economic order in diverse forms, to ensure smooth working of human society." To conclude our article, we can say that, though even now adamant advocates of various old and new 
political and socio-economic and fundamentalist systems, sharing common vested interest in retaining a hold on power threaten human Civilisation with the risk of nuclear-chemical annihilation, on the balance of probability, there are reasonable prospects for realisation of $\mathbf{J}$. Tuma's prediction of emergence of a new socio-economic order from the mix of classical liberal and idealist solidarist systems. We have now reached the sign-post directing us to the New World. Bertrand Russel - Prophet of our scientific age - had predicted this ultimate goal of human civilisation way back in 1951 with the following words:

"When the conquest of Nature has secured the possibility of nourishment for everybody and when the growth of technique has made large scale co-operation profitable, the conflict of Man with Man becomes an Anachronism and should end in Political and Economic Unification, such as is sought by advocates of World Government." A fitting welcome to this Brave New World, emerging from the synthesis of diverse socio-economic-political and cultural norms in the furnace of scientific progress can be given by singing a prayer composed by the youngest poet philosopher of India, Saint Dnyaneshwer in A.D. 1290:

"Let all creatures be firiends, May the gloom of evil vanish,

And each one find what he seeks,

And $\mathrm{He}$ who makes this work his life blood,

May He triumph over the seen and the unseen." 